\title{
Dose-response relationships for enzyme replacement therapy with imiglucerase/alglucerase in patients with Gaucher disease type 1
}

\author{
Gregory A. Grabowski, $M D^{1}$, Katherine Kacena, $P h D^{2}$, J. Alexander Cole, DSc, MPH ${ }^{2}$, \\ Carla E. M. Hollak, $M D^{3}$, Lin Zhang, MD, PhD ${ }^{2}$, John Yee, $M D^{4}$, Pramod K. Mistry, MD, PhD ${ }^{5}$, \\ Ari Zimran, $M D^{6}$, Joel Charrow, $M D^{7}$, and Stephan vom Dahl, $M D^{8}$
}

\begin{abstract}
Purpose: To determine whether enzyme therapy with imiglucerase/ alglucerase demonstrates dose-response relationships with doses and disease parameters used in routine clinical practice for Gaucher disease type 1 patients. Methods: Analyses included all patients with Gaucher disease type 1 on enzyme therapy and with intact spleens in the large observational database of the International Collaborative Gaucher Group Gaucher Registry. Propensity scoring was used to match patients between enzyme therapy dose groups categorized as Group A (5 U to $<29 \mathrm{U} / \mathrm{kg} / 2$ weeks), Group B ( $29 \mathrm{U}$ to $<48 \mathrm{U} / \mathrm{kg} / 2$ weeks), Group C ( $48 \mathrm{U}$ to $<75 \mathrm{U} / \mathrm{kg} / 2$ weeks). Hemoglobin concentration, platelet count, and hepatic and splenic volumes were assessed after initiation of enzyme therapy using nonlinear mixed effects models. The maximal effect $\left(E_{\max }\right)$ and half-time to $E_{\max }\left(T_{50}\right)$ of enzyme therapy for each parameter
\end{abstract}

From the ${ }^{1}$ Cincinnati Children's Hospital Medical Center, Cincinnati, Ohio; ${ }^{2}$ Biostatistics/Epidemiology, Genzyme Corporation, Cambridge, Massachusetts; ${ }^{3}$ Academic Medical Center, Amsterdam, The Netherlands; ${ }^{4}$ Global Medical Affairs, Genzyme Corporation, Cambridge, Massachusetts; ${ }^{5}$ Yale University School of Medicine, New Haven, Connecticut; ${ }^{6}$ Shaare-Zedek Medical Center, Jerusalem, Israel; ${ }^{7}$ Children's Memorial Hospital and Feinberg School of Medicine, Northwestern University, Chicago, Illinois; and ${ }^{8}$ St. Franziskus-Hospital, Cologne, Academic Teaching Hospital, University of Cologne, Germany.

Gregory A. Grabowski, MD, Cincinnati Children's Hospital Medical Center, Division of Human Genetics, 3333 Burnet Avenue, MLC 4006, Cincinnati, OH 45229-3039. E-mail: greg.grabowski@cchmc.org.

Katherine Kacena is currently at Molecular Insight Pharmaceuticals, Cambridge, Massachusetts.

Lin Zhang is currently at Bristol-Myers Squibb Company, Pennington, New Jersey.

Drs. Gregory A. Grabowski and Katherine Kacena contributed equally to this work.

Gregory A. Grabowski had full access to all of the data in the study and takes responsibility for the integrity of the data and the accuracy of the data analysis.

Disclosure: The authors declare the following financial disclosures: Gregory A. Grabowski: consultant (Genzyme Corporation), Advisory Board (HGT/Shire), basic research grants (Genzyme Corp., HGT/Shire, Amicus Corp.), Speakers Bureau (Genzyme, HGT/Shire), Research grants (NIH-4, FDA - 1, State of Ohio - 2). Katherine Kacena: employee of Genzyme Corp. during the period of statistical analyses. Lin Zhang: employee of Genzyme Corp. during the period of statistical analyses. John Yee: employee of Genzyme Corp. Pramod Mistry: Speakers Bureau (Genzyme Corp.), fellowship grant for training the lysosomal diseases. Ari Zimran: consultant (HGT/Shire, Protalix Biopharmaceutics), Scientific Advisory Board (Protalix), stock options (Protalix), Speakers Bureau (Actelion), Registry Grant (Genzyme Corp.). Joel Charrow: ICGG and Fabry Registry grants (Genzyme Corp.). Stephan vom Dahl: consultant, Speakers Bureau and educational grant (Genzyme Corp.).

Supplemental digital content is available for this article. Direct URL citations appear in the printed text and are provided in the HTML and PDF versions of this article on the journal's Web site (www.geneticsinmedicine.org).

Submitted for publication March 14, 2008

Accepted for publication September 16, 2008

DOI: 10.1097/GIM.0b013e31818e2c19 were compared across dosing groups. Results: Propensity score matching resulted in three comparable groups of 122 patients each (enzyme therapy in Groups A, B, and C). Dose-response relationships were found with regard to $E_{\max }$ and $T_{50}$ over 96 months for each disease parameter. Conclusions: Enzyme therapy with imiglucerase/alglucerase displays a dose-dependent improvement in hematological and visceral parameters in Gaucher disease type 1 patients. Group C displayed greater treatment effects than Groups A or B. Propensity score matching and nonlinear mixed effects model analyses provide a prototype for assessment of treatment outcomes based on observational data from international rare disease registries. Genet Med 2009:11(2):92-100.

Key Words: propensity scoring, inborn errors of metabolism, lysosomal storage disease, sphingolipids

G aucher disease (GD) is a lysosomal storage disorder that results from insufficient clearance of cellular glucosylceramide, the substrate for the lysosomal enzyme, acid $\beta$-glucosidase (EC 3.2.1.45; glucocerebrosidase). The pathologic accumulations of glucosylceramide in lysosomes of tissue macrophages results in splenomegaly, hepatomegaly, anemia, thrombocytopenia, and multiple forms of skeletal pathology. ${ }^{1-5}$ In the Western world, GD type 1 (GD1) is the most prevalent variant $(94 \%)$ and is classically differentiated from types $2(1 \%)$ and $3(5 \%)$ by the absence of primary central nervous system involvement. ${ }^{1,6} \mathrm{GD} 1$ is an ultraorphan disease, with an estimated worldwide prevalence of 1 in 60,000 .?

The current standard of care for the treatment of GD1 is enzyme replacement (or more appropriately, reconstitution) therapy with imiglucerase, a recombinant form of glucocerebrosidase. Alglucerase, derived from placental tissue, was used before the availability of imiglucerase. A randomized clinical trial comparing alglucerase and imiglucerase found these enzymes to be therapeutically equivalent in safety and efficacy. ${ }^{8}$

Whether enzyme therapy has dose-dependent treatment effects has been a subject of debate since the first clinical trial of alglucerase was published in 1991. ${ }^{9}$ In 1995, a panel convened by the National Institutes of Health highlighted the importance of determining whether enzyme therapy has dose-dependent treatment effects. ${ }^{10}$ Dosing practices for enzyme therapy have varied around the world because, in part, of the lack of clear evidence of doseresponse relationships. ${ }^{911-15}$ For patients with bone disease or other severe manifestations of GD, the recommendation has been to use higher doses. ${ }^{16,17}$ Given the high cost of therapy and the great phenotypic heterogeneity between patients with GD1, the goal of treatment has been to identify individualized dosing regimens that can achieve optimal long-term outcomes for each patient. ${ }^{18}$

Ideally, dose-response relationships would be evaluated by conducting a randomized clinical trial with multiple arms. For rare diseases, such as GD1, this study design would not be practical or feasible because of the large number of subjects and 
length of follow-up needed to achieve adequate statistical power. As an alternative, analyses of observational data from a large international disease registry using standard epidemiologic matching and modeling methods may offer a feasible and methodologically sound approach.

In the present analyses, data from the International Collaborative Gaucher Group (ICGG) Gaucher Registry were analyzed using propensity scoring methods to match patients between dosing groups ${ }^{19-22}$ to approximate conditions under a randomized trial. Nonlinear mixed effects modeling of these matched data sets was used to assess dose-response relationships across disease parameters.

\section{MATERIALS AND METHODS}

\section{ICGG Gaucher registry}

The ICGG Gaucher Registry was established in 1991 to track the clinical, biochemical, and therapeutic response characteristics of patients with GD, irrespective of disease severity and treatment status. ${ }^{6}$ The main objectives of the Registry are to define the characteristics of GD and assess the long-term outcomes of treatment. The Registry receives scientific direction from an independent international group of physician experts in GD, and operational and financial support from Genzyme Corporation (Cambridge, MA). With appropriate Institutional Review Board/Ethics Committee approvals, over 700 physicians from 60 countries have voluntarily submitted anonymized patient data to the Registry since 1991.

\section{Study population}

As of August 4, 2006, 4434 patients with GD were enrolled in the ICGG Gaucher Registry. The dataset for the present analyses included all GD1 patients enrolled who had been diagnosed after January 1, 1991 (the inception of the Registry), had received enzyme therapy with either alglucerase (Ceredase ${ }^{\circledR}$, Genzyme Corporation, Cambridge, MA) or imiglucerase (Cerezyme ${ }^{\circledR}$, Genzyme Corporation, Cambridge, MA), and who had not had a partial or total splenectomy $(n=1238)$. In the present study, $95.6 \%$ of patients received imiglucerase, whereas $4.4 \%$ only received alglucerase. For the purposes of this analysis, enzyme therapy refers to alglucerase and/or imiglucerase treatment.

The diagnosis of GD1 was based on clinical parameters and the defective activity of acid $\beta$-glucosidase activity in peripheral blood leukocytes or cultured skin fibroblasts, and/or genotyping of the glucocerebrosidase gene. Included patients had at least one recorded observation at baseline (around the time of first infusion of enzyme therapy) among the following hematological and visceral parameters: hemoglobin concentration, platelet count, and hepatic or splenic volume $(n=948)$. The following date ranges at baseline were referenced: hemoglobin concentration and platelet counts from 6 months before through 0.5 months after first imiglucerase/ alglucerase infusion; hepatic and splenic volumes from 12 months before through 6 months after first infusion of enzyme therapy. The final group of patients eligible for propensity score matching was the subset who had all four hematological and visceral parameters recorded on or after the first infusion of enzyme therapy $(n=586)$. Importantly, this patient dataset and the final matched patient dataset $(n=366)$ had disease parameter characteristics that were representative of the entire patient dataset across all parameters from the original dataset of patients $(n=1238)$ (see Table, Supplemental Digital Content 1, http://links.lww.com/A694).

\section{Dose of Enzyme Replacement Therapy}

Enzyme therapy dosing data are typically recorded in the Registry at the time of first infusion, at any dose change, and periodically if no change was made. Because the ICGG Gaucher Registry does not require adherence to specific dosing protocols, physicians can adjust dose levels up or down at their discretion after initiation of therapy. To account for this variation, the average dose of enzyme therapy across the initial 3 years of therapy was calculated for each patient and then categorized into three groups: Group A ( 5 to $<29 \mathrm{U} / \mathrm{kg} / 2$ weeks), Group B ( 29 to $<48 \mathrm{U} / \mathrm{kg} / 2$ weeks), and Group C (48 to $<75$ $\mathrm{U} / \mathrm{kg} / 2$ weeks). When the number of years after initiation of therapy as the basis for calculating average dose of enzyme therapy was varied, the results were consistent (see Table, Supplemental Digital content 2, http://links.lww.com/A695). The age distributions within each dosing group are in Table, Supplemental Digital Content 3, http://links.lww.com/A696.

\section{Outcomes}

The study outcomes were changes in hemoglobin concentration, platelet count, and hepatic and splenic volumes (multiples of normal). These were selected as the parameters most frequently analyzed in previous clinical trials and the parameters with the most data available in the ICGG Gaucher Registry. Hemoglobin was normalized and analyzed as the actual values minus the lower limit of normal for age and sex, as follows: $<6$ months, $<10.1$ (g/dL); 6 months -2 years, $<9.5(\mathrm{~g} / \mathrm{dL}) ;>2-12$ years, $<10.5(\mathrm{~g} / \mathrm{dL})$; male $>12$ years, $<12(\mathrm{~g} / \mathrm{dL})$; and female $>12$ years, $<11(\mathrm{~g} / \mathrm{dL})$. Hepatic and splenic volumes were determined by magnetic resonance imaging, computed tomography, or ultrasonography and reported as multiples of normal. Ultrasound measurements were converted to volumetric equivalents using the formula previously developed. ${ }^{23}$

\section{Propensity score matching}

To limit potential confounding by indication (e.g., greater disease severity in the higher dosing groups), the propensity score matching method was used to identify comparable groups of patients across relevant variables associated with initiation of enzyme therapy. ${ }^{20}$ The propensity score, calculated through a logistic regression model, represented the probability of being in the Group $\mathrm{C}$ dose group relative to the other two combined groups (Groups A and $\mathrm{B}$ ). The following variables were included in the logistic regression model: age at diagnosis, age at first infusion, values of hemoglobin and platelet levels, and hepatic and splenic volumes at the time of first infusion of enzyme therapy. Not all patients had measurements for hemoglobin, platelet, hepatic volume, and splenic volume recorded in the Registry precisely at the time of first infusion. Therefore, nonlinear mixed effects models were used to impute values of these variables at the time of first infusion. The consistency of the distribution of baseline disease parameters in the final analysis population $(n=366)$ with the entire patient datasets (either $n=586$ or $n=1238$ ) provided confidence in the imputed values (Tables 1, Supplemental Digital Content 1, http://links.lww.com/A694). Patients from the Groups A and B were individually matched to members of Group C within a range of 0.025 of the propensity score.

\section{Dose-response analysis}

To analyze the effect of dose, nonlinear mixed effects models using the maximal effect of dose $\left(E_{\max }\right)$ parameterization $^{24}$ were constructed for each of the four study outcomes. This parameterization permitted estimation of the $E_{\max }$ along with the time required to achieve $50 \%$ of the 
Table 1 Baseline patient characteristics for all dosing groups before and after matching ${ }^{a}$

\begin{tabular}{|c|c|c|c|c|c|c|c|c|}
\hline & \multicolumn{4}{|c|}{ Before matching } & \multicolumn{4}{|c|}{ After matching } \\
\hline & $\begin{array}{c}\text { Group A } \\
5 \text { to }<29 \\
\mathrm{U} / \mathrm{kg} / 2 \mathrm{wk} \\
(N=171)\end{array}$ & $\begin{array}{c}\text { Group B } \\
29 \text { to }<48 \\
\mathrm{U} / \mathrm{kg} / 2 \mathrm{wk} \\
(N=210)\end{array}$ & $\begin{array}{l}\text { Group } \mathrm{C} \\
48 \text { to }<75 \\
\mathrm{U} / \mathrm{kg} / 2 \mathrm{wk} \\
(N=205)\end{array}$ & $P$ & $\begin{array}{c}\text { Group } \mathrm{A} \\
5 \text { to }<29 \\
\mathrm{U} / \mathrm{kg} / 2 \mathrm{wk} \\
(N=122)\end{array}$ & $\begin{array}{c}\text { Group B } \\
29 \text { to }<48 \\
\mathrm{U} / \mathrm{kg} / 2 \mathrm{wk} \\
(N=122)\end{array}$ & $\begin{array}{l}\text { Group } \mathrm{C} \\
48 \text { to }<75 \\
\mathrm{U} / \mathrm{kg} / 2 \mathrm{wk} \\
(N=122)\end{array}$ & $P$ \\
\hline $\begin{array}{l}\text { Age at diagnosis, } \\
\text { mean (SD) }\end{array}$ & $22.9(20.0)$ & $20.8(20.2)$ & $17.2(17.8)$ & 0.02 & $20.5(20.1)$ & $20.9(19.7)$ & $21.5(19.7)$ & 0.92 \\
\hline $\begin{array}{c}\text { Age at baseline, } \\
\text { mean (SD) }\end{array}$ & $25.1(20.2)$ & $22.4(20.7)$ & $18.5(18.1)$ & $<0.01$ & $22.1(19.9)$ & $22.6(19.9)$ & $23.1(19.8)$ & 0.92 \\
\hline $\begin{array}{l}\text { Hemoglobin, } \\
\text { normalized }^{b} \\
\text { (g/dL), mean } \\
\text { (SD) }\end{array}$ & $0.3(1.0)$ & $0.4(0.8)$ & $0.2(1.0)$ & 0.13 & $0.3(1.0)$ & $0.5(0.8)$ & $0.3(1.0)$ & 0.25 \\
\hline $\begin{array}{l}\text { Platelet count } \\
\qquad\left(\times 10^{3} / \mathrm{mm}^{3}\right) \\
\text { mean }(\mathrm{SD})\end{array}$ & $90.2(33.1)$ & $93.1(28.1)$ & $98.7(30.6)$ & 0.02 & $95.2(34.5)$ & $92.4(26.7)$ & $94.1(31.1)$ & 0.78 \\
\hline $\begin{array}{l}\text { Splenic volume } \\
\text { (multiples of } \\
\text { normal), mean } \\
\text { (SD) }\end{array}$ & $14.2(8.3)$ & $13.1(11.4)$ & $12.6(8.1)$ & 0.27 & $13.4(6.9)$ & $13.0(11.4)$ & $13.1(8.9)$ & 0.94 \\
\hline $\begin{array}{l}\text { Hepatic volume } \\
\text { (multiples of } \\
\text { normal), mean } \\
\text { (SD) }\end{array}$ & $1.5(0.4)$ & $1.5(0.5)$ & $1.4(0.4)$ & 0.04 & $1.5(0.3)$ & $1.5(0.5)$ & $1.5(0.4)$ & 0.65 \\
\hline \multicolumn{9}{|c|}{$\begin{array}{l}{ }^{a} \text { For the purpose of propensity score modeling, patients without reported baseline values for hemoglobin, platelet count, splenic volume, or hepatic volume had values } \\
\text { imputed through nonlinear mixed effects models. Distribution of baseline values among patients with reported data is shown in Supplemental Digital Content } 1 \text {, } \\
\text { http://links.lww.com/A694. } \\
{ }^{b} \mathrm{Hemoglobin} \text { was analyzed as real values in } \mathrm{g} / \mathrm{dL} \text { minus the cutoff for anemia defined as below the normal age- and gender-adjusted value as follows: }<6 \text { mo, }<10.1 \\
(\mathrm{~g} / \mathrm{dL}) ; 6 \mathrm{mo}-2 \mathrm{yr},<9.5(\mathrm{~g} / \mathrm{dL}) ;>2-12 \mathrm{yr},<10.5(\mathrm{~g} / \mathrm{dL}) ; \text { male }>12 \mathrm{yr},<12(\mathrm{~g} / \mathrm{dL}) \text {; and female }>12 \mathrm{yr},<11 \text { (g/dL). For example, a female adult with hemoglobin of } \\
13 \mathrm{~g} / \mathrm{dL} \text { would have hemoglobin of } 2 \mathrm{~g} / \mathrm{dL} \text { relative to the cutoff for anemia. }\end{array}$} \\
\hline
\end{tabular}

maximal effect $\left(T_{50}\right)$. This $T_{50}$ value differs significantly in meaning from two more familiar such values: (1) A $T_{1 / 2}$ has been used in many enzyme therapy studies to represent the time to a $50 \%$ change in outcome parameter, e.g., time to a $50 \%$ reduction in splenic volume and (2) the $t_{1 / 2}$ as the typical pharmacokinetic disappearance half-life of imiglucerase/alglucerase in plasma/serum. Because the distributions of platelet count, splenic volume, and hepatic volume were skewed, these parameters were $\log$ transformed for the purpose of model construction. Therefore, the $E_{\max }$ is interpreted as a relative change from the time of first infusion for these outcomes. Results from the models are depicted in both graphical and tabular formats. Nonparametric Loess curves of the outcomes were evaluated to confirm that the $E_{\max }$ parameterization was the appropriate form of the nonlinear mixed model.

Sensitivity analyses were conducted for the matched $(n=$ $366)$ and unmatched $(n=586)$ datasets to estimate the robustness of the final model by including terms for the propensity score main, along with interactions between the propensity score and $E_{\max }$ and $T_{50}$ parameters. All analyses were conducted in SAS 8.2 (SAS Institute Inc., Cary, NC).

\section{RESULTS}

Patient characteristics are shown before $(n=586)$ and after propensity score matching in Table $1(n=366 ; 122$ patients in each of three dosing groups). Before matching, the three groups differed significantly across several parameters: age at diagnosis $(P=0.02)$, age at baseline $(P<0.01)$, platelet count $(P=0.02)$, and hepatic volume $(P=0.04)$. After matching, there were no statistically significant differences between the three dosing groups (Table 1). These matched sets were used for all final analyses. Dose-response relationships were found for each parameter: hemoglobin concentration, platelet count, splenic volume, and hepatic volume. For all four parameters, Group $\mathrm{C}$ achieved highest maximal treatment effects.

For hemoglobin concentration, the model results are shown in Figure 1, A and B. For Group A, the $E_{\max }$ for hemoglobin was an increase of $1.45 \mathrm{~g} / \mathrm{dL}$ above baseline and the $T_{50}$ was 3.76 months. For Group B, the $E_{\max }$ was an increase of 1.74 $\mathrm{g} / \mathrm{dL}$ from baseline and $T_{50}$ was 4.21 months. The $E_{\max }$ and $T_{50}$ values for Group $\mathrm{C}$ were $2.32 \mathrm{~g} / \mathrm{dL}$ and 5.28 months, respectively. Furthermore, the plateaus in responses out to 96 months were maintained with stratification by the three dosing groups.

For platelet counts (Fig. 2, A and B), Group A showed $E_{\max }$ and $T_{50}$ of 1.97-fold increase from baseline and 18.09 months, respectively. In comparison, Groups B and $\mathrm{C}$ differed from the lowest dose group, with the Group $\mathrm{C}$ having the greatest response with $E_{\max }$ of 2.1-fold increase from baseline and $T_{50}=$ 4.83 months. The curves seem to be converging beyond 96 months of ERT to a level of $\sim 2.2$ to 2.3 -fold increase above baseline in all three groups. However, the rates of response to dose clearly segregate between 0 and 60 months of enzyme therapy. A greater response rate was evident in Group $\mathrm{C}$ compared with either Groups A or B.

Splenic volume dose-response relationships are shown in Figure $3, \mathrm{~A}$ and $\mathrm{B}$. The $E_{\max }$ values were $0.32,0.22$, and 0.10 from baseline for Groups A, B, and C, respectively, correspond- 
A

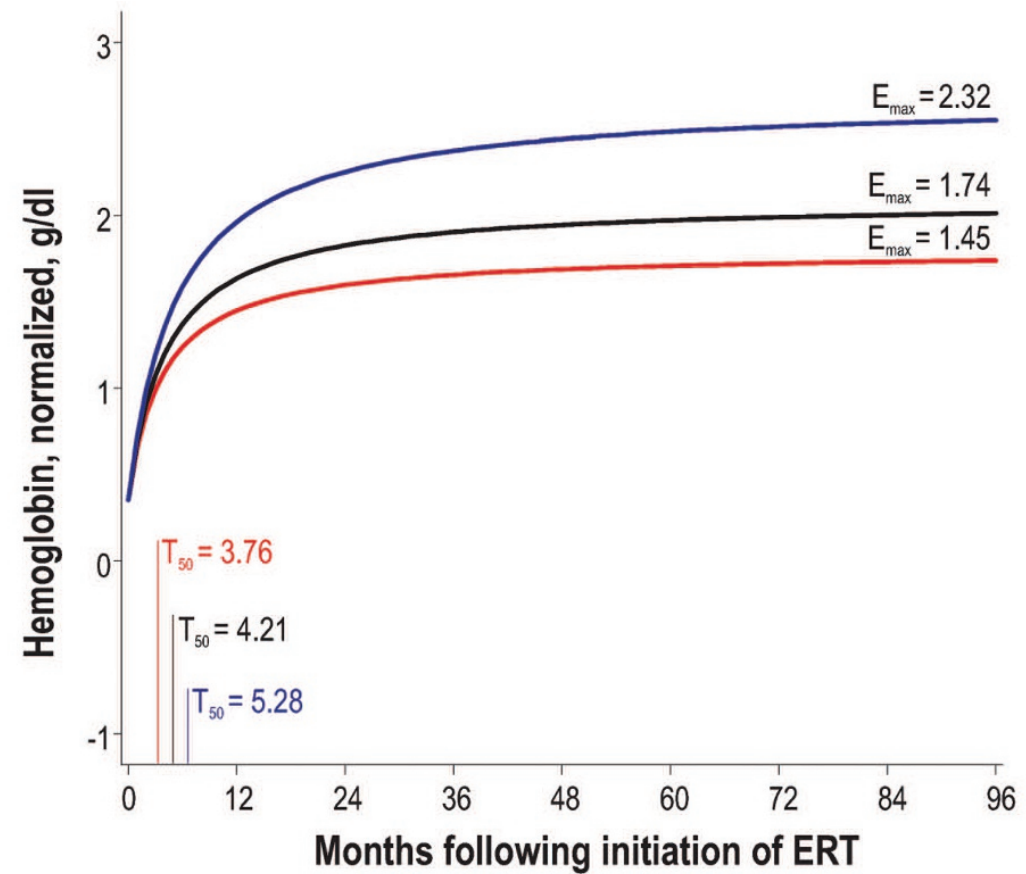

B

\begin{tabular}{|c|c|c|c|c|}
\hline Parameter & $\begin{array}{l}\text { Hemoglobin, } \\
\text { normalized, g/dL }\end{array}$ & \multicolumn{2}{|c|}{$95 \% \mathrm{Cl}$} & \multirow[t]{2}{*}{ p-value } \\
\hline $\mathrm{E}_{\max }$ & $\begin{array}{l}\text { Absolute change } \\
\text { from baseline }\end{array}$ & & & \\
\hline 48 to $<75 \mathrm{U} / \mathrm{kg} / 2 \mathrm{wk}$ & 2.32 & 2.13 & 2.51 & \multirow{3}{*}{$<0.01$} \\
\hline 29 to $<48 \mathrm{U} / \mathrm{kg} / 2 \mathrm{wk}$ & 1.74 & 1.61 & 1.85 & \\
\hline 5 to $<29 \mathrm{U} / \mathrm{kg} / 2 \mathrm{wk}$ & 1.45 & 1.27 & 1.61 & \\
\hline $\mathrm{T}_{50}$ & Months & & & \\
\hline 48 to $<75 \mathrm{U} / \mathrm{kg} / 2 \mathrm{wk}$ & 5.28 & 3.90 & 7.14 & \multirow{3}{*}{0.28} \\
\hline 29 to $<48 \mathrm{U} / \mathrm{kg} / 2 \mathrm{wk}$ & 4.21 & 3.17 & 5.62 & \\
\hline 5 to $<29 \mathrm{U} / \mathrm{kg} / 2 \mathrm{wk}$ & 3.76 & 2.41 & 5.91 & \\
\hline
\end{tabular}

* $\mathrm{p}$-value indicates statistical significance among dosing groups.

Fig. 1. Hemoglobin concentration dose responses to enzyme therapy. A, Nonlinear mixed model showing the doseresponse relationships of matched patients for normalized hemoglobin concentrations. In each dosing group, the total numbers of data points used to generate the curves and values after matching were 1684 for Group A $(5$ to $<29 \mathrm{U} / \mathrm{kg} / 2$ weeks, red), 1845 for Group B ( 29 to $<48 \mathrm{U} / \mathrm{kg} / 2$ weeks, black) and 1409 for Group C (48 to $<75 \mathrm{U} / \mathrm{kg} / 2$ weeks, blue). B, Table of calculated values from (A) for maximal effect from baseline $\left(E_{\max }\right)$ and time to $50 \%$ of maximal effect $\left(T_{50}\right)$. The $P$ values are overall for the three dosing groups, and the absence of small overlaps in the $95 \%$ confidence intervals indicate the differences between the groups.

ing to reductions of $68 \%, 78 \%$, and $90 \%$ in splenic volumes from baseline. For the $T_{50}$ values, the $95 \%$ confidence intervals were larger, particularly for the Group C dose group bounded by $93 \%$ and $86 \%$ reductions in splenic volumes. A clear difference between the groups was evident in $E_{\max }$ from the nonoverlapping 95\% confidence intervals between the Groups A, B, or C. The rates of reductions stratified after $\sim 12$ months with greater reductions in Group C.
The dose-response relationships for changes in hepatic volume are presented in Figure 4, A and B. For Groups A, B, and C, the $E_{\max }$ for hepatic volume decreases were $0.61,0.49$, and 0.31 , respectively, from baseline corresponding to $39 \%, 51 \%$, and $69 \%$ reductions. Both the dose-dependent effects for $E_{\max }$ and $T_{50}$ were statistically significant at $P<0.01$. The initial differences for hepatic volume reductions were not as apparent as for the other parameters, but the $E_{\max }$ values clearly diverged beyond 60 months. 
A

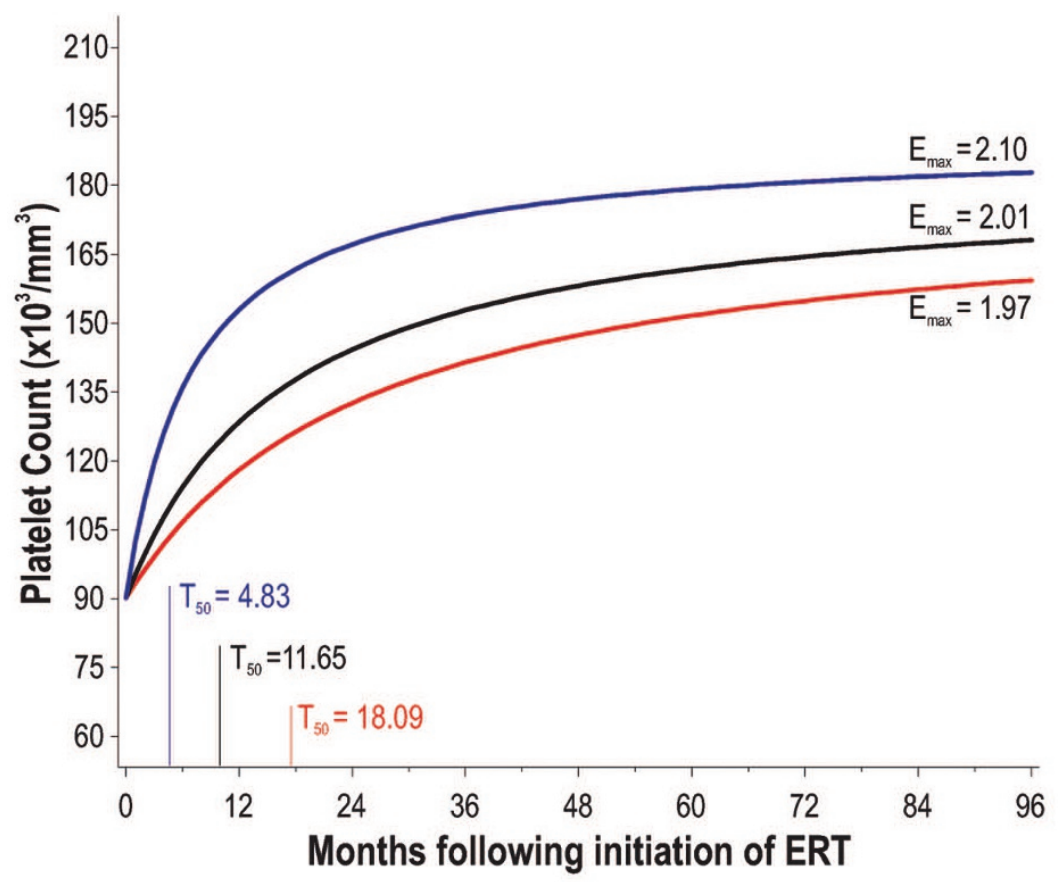

B

\begin{tabular}{|c|c|c|c|c|}
\hline Parameter & $\begin{array}{l}\text { Platelet } \\
\text { Counts }\end{array}$ & \multicolumn{2}{|c|}{$95 \% \mathrm{Cl}$} & p-value* \\
\hline $\mathrm{E}_{\max }$ & $\begin{array}{l}\text { Relative change } \\
\text { from baseline }\end{array}$ & & & \\
\hline 48 to $<75 \mathrm{U} / \mathrm{kg} / 2 \mathrm{wk}$ & 2.10 & 1.99 & 2.21 & \\
\hline 29 to $<48 \mathrm{U} / \mathrm{kg} / 2 \mathrm{wk}$ & 2.01 & 1.95 & 2.08 & 0.13 \\
\hline 5 to $<29 \mathrm{U} / \mathrm{kg} / 2 \mathrm{wk}$ & 1.97 & 1.87 & 2.07 & \\
\hline $\mathrm{T}_{50}$ & Months & & & \\
\hline 48 to $<75 \mathrm{U} / \mathrm{kg} / 2 \mathrm{wk}$ & 4.83 & 3.74 & 6.22 & \\
\hline 29 to $<48 \mathrm{U} / \mathrm{kg} / 2 \mathrm{wk}$ & 11.65 & 9.66 & 14.04 & $<0.01$ \\
\hline 5 to $<29 \mathrm{U} / \mathrm{kg} / 2 \mathrm{wk}$ & 18.09 & 13.39 & 24.44 & \\
\hline
\end{tabular}

"p-value indicates statistical significance among dosing groups.

Fig. 2. Platelet count dose responses to enzyme therapy. A, Nonlinear mixed model showing the dose-response relationships of matched patients for platelet count. The $E_{\max }$ values were 1.97, 2.01, and 2.10 from baseline for Group A (5 to $<29 \mathrm{U} / \mathrm{kg} / 2$ weeks), Group B ( 29 to $<48 \mathrm{U} / \mathrm{kg} / 2$ weeks), and Group C (48 to $<75 \mathrm{U} / \mathrm{kg} / 2$ weeks) dosing groups, respectively, corresponding to an approximately 2-fold increase in platelet count by 96 months. In each dosing group, the total number of data points after matching were 1679 for Group A (red), 1850 for Group B (black), and 1411 for Group $C$ (blue). B, Table of calculated values for maximal effect from baseline $\left(E_{\max }\right)$ and time to $50 \%$ of maximal effect $\left(T_{50}\right)$. The $P$ values and $95 \%$ confidence intervals are as in Figure 1B.

As a sensitivity analysis, all models for both unmatched $(n=568)$ and matched $(n=366)$ datasets were reproduced using dose categories derived from average dose levels across the initial $1,2,3,4,5$, and 8 years of therapy. These are summarized in Table, Supplemental Digital Content 4, http://links.lww.com/A697 and Table, Supplemental Digital Content 5, http://links.lww.com/A686 and show a robust model for each of the four disease parameters analyzed. The results did not differ substantially from those obtained from the dose averaged across the initial 3 years of follow-up.

\section{DISCUSSION}

In this study, enzyme therapy dose-response relationships for GD1 were found with alglucerase and/or imiglucerase across the main hematological and visceral manifestations of GD1 within the 


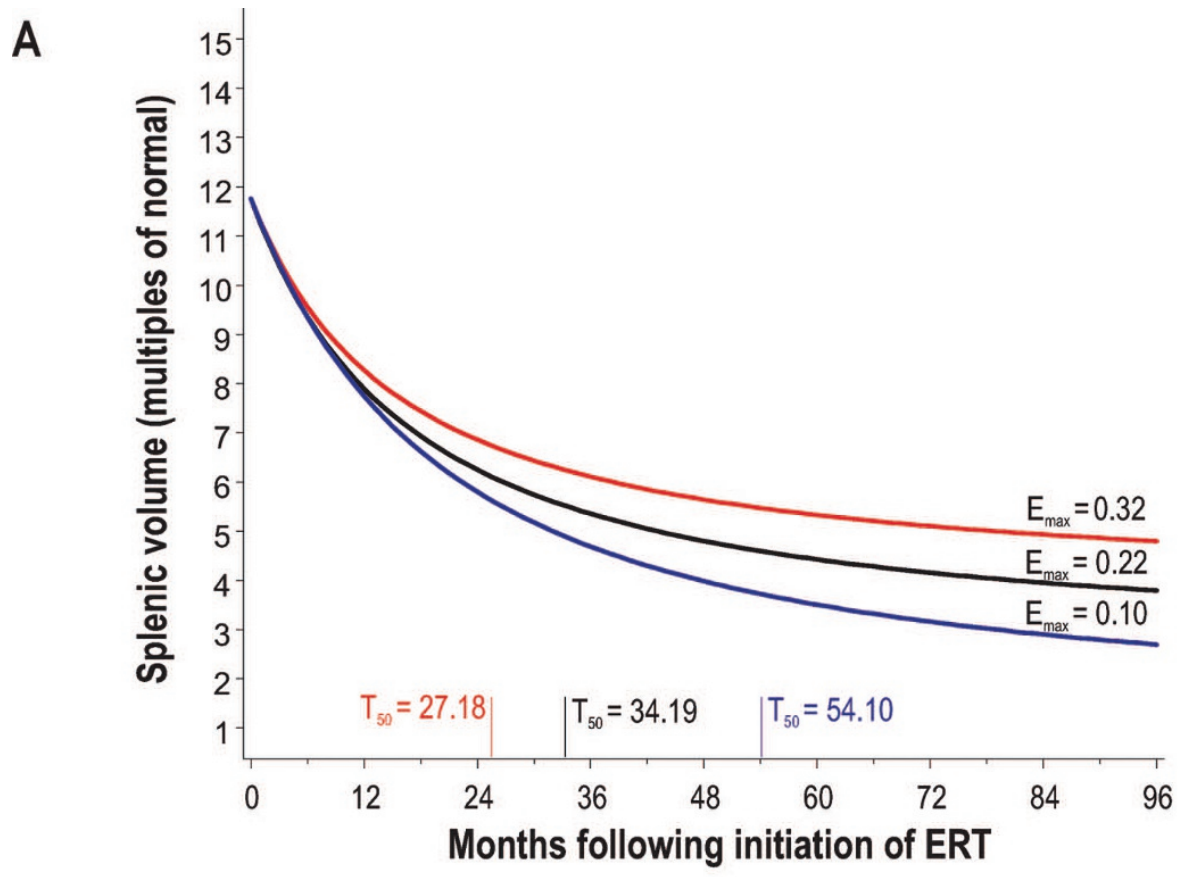

B

\begin{tabular}{|c|c|c|c|c|}
\hline Parameter & $\begin{array}{l}\text { Splenic } \\
\text { Volume }\end{array}$ & \multicolumn{2}{|c|}{$95 \% \mathrm{Cl}$} & $p$-value \\
\hline $\mathrm{E}_{\max }$ & $\begin{array}{l}\text { Relative change } \\
\text { from baseline }\end{array}$ & & & \\
\hline 48 to $<75 \mathrm{U} / \mathrm{kg} / 2 \mathrm{wk}$ & 0.10 & 0.07 & 0.14 & \\
\hline 29 to $<48 \mathrm{U} / \mathrm{kg} / 2 \mathrm{wk}$ & 0.22 & 0.19 & 0.24 & $<0.01$ \\
\hline 5 to $<29 \mathrm{U} / \mathrm{kg} / 2 \mathrm{wk}$ & 0.32 & 0.27 & 0.37 & \\
\hline $\mathrm{T}_{50}$ & Months & & & \\
\hline 48 to $<75 \mathrm{U} / \mathrm{kg} / 2 \mathrm{wk}$ & 54.10 & 30.01 & 97.51 & \\
\hline 29 to $<48 \mathrm{U} / \mathrm{kg} / 2 \mathrm{wk}$ & 34.19 & 26.31 & 44.42 & 0.10 \\
\hline 5 to $<29 \mathrm{U} / \mathrm{kg} / 2 \mathrm{wk}$ & 27.18 & 18.43 & 40.07 & \\
\hline
\end{tabular}

p-value indicates statistical significance among dosing groups.

Fig. 3. Splenic volume dose responses to enzyme therapy. A, Nonlinear mixed model showing the dose-response relationships of matched patients for splenic volume. The $E_{\max }$ values were $0.32,0.22$, and 0.10 from baseline for the Group A ( 5 to $<29 \mathrm{U} / \mathrm{kg} / 2$ weeks), Group B (29 to $<48 \mathrm{U} / \mathrm{kg} / 2$ weeks), and Group C (48 to $<75 \mathrm{U} / \mathrm{kg} / 2$ weeks) dosing groups, respectively, corresponding to reductions of $68 \%, 78 \%$, and $90 \%$ in splenic volumes. The number of data points in each dosing group after matching was 521 for Group A (red), 482 for Group B (black), and 347 for Group C (blue). B, Table of calculated values from (A) for maximal effect from baseline $\left(E_{\max }\right)$ and time to $50 \%$ of maximal effect $\left(T_{50}\right)$ responses to splenic volume. The $P$ values and $95 \%$ confidence intervals are as in Figure $1 \mathrm{~A}$.

range of doses typically used in clinical practice. This study was designed to address the question of dose response. In that respect, the outcomes of the study will certainly be of value when considering individual choices for treatment dose. However, in the absence of a validated outcome score and consensus agreement on the appropriate clinical responses, it is not yet possible to provide general clinical guidelines; this also applies to costs. Clearly, future studies will need to address these important, critical issues, but are beyond the scope of this current work (see below). The findings here show that the dose of enzyme therapy affected the level of maximal treatment effect $\left(E_{\max }\right)$ across the disease parameters studied (i.e., the higher dose groups achieved a higher maximal level of treatment effect). For most parameters, the $T_{50}$ also seemed to be dose dependent.

The results of this study differ from previous studies, which did not identify dose-response relationships for alglucerase or 


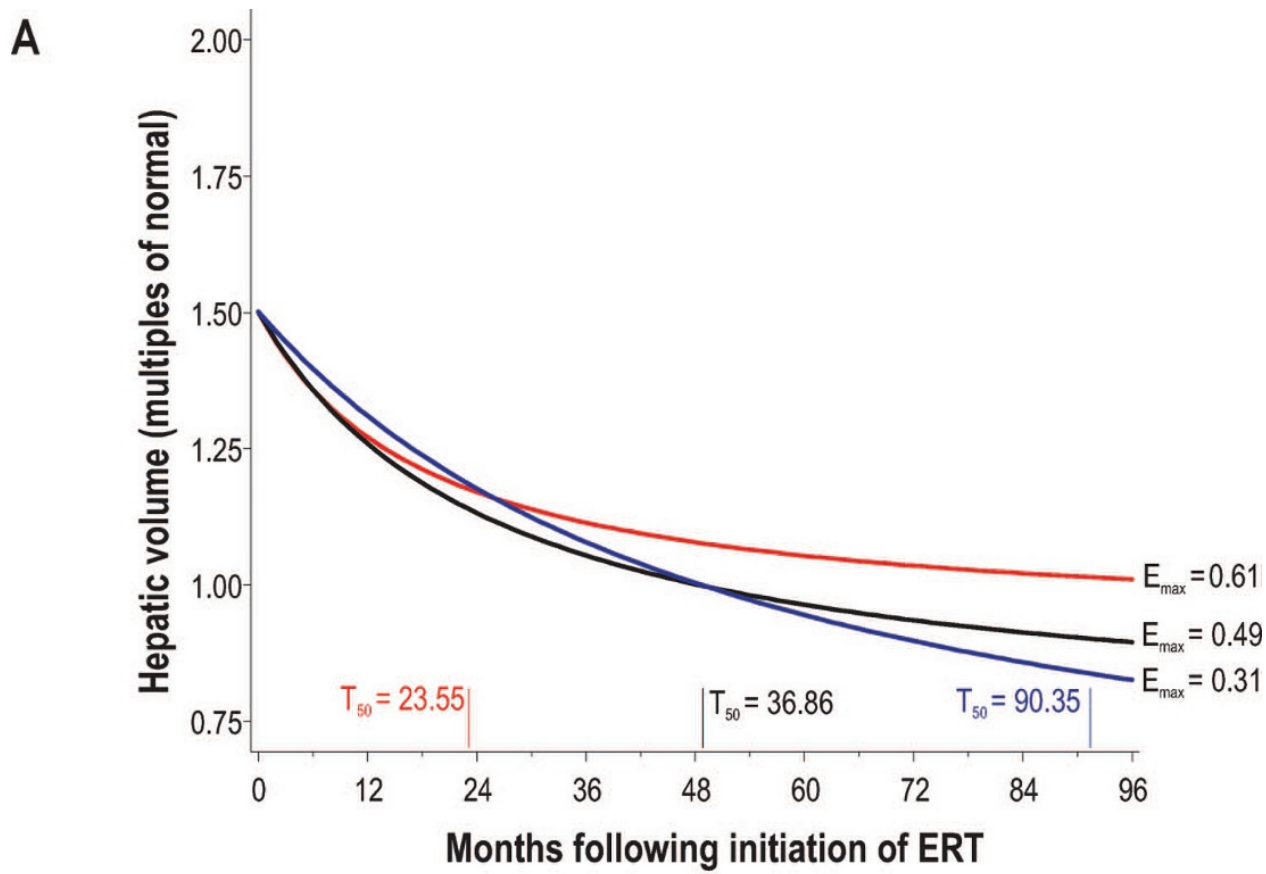

\begin{tabular}{|c|c|c|c|c|}
\hline Parameter & $\begin{array}{l}\text { Hepatic } \\
\text { Volume }\end{array}$ & \multicolumn{2}{|c|}{$95 \% \mathrm{Cl}$} & p-value* \\
\hline$E_{\text {max }}$ & $\begin{array}{l}\text { Relative change } \\
\text { from baseline }\end{array}$ & & & \\
\hline 48 to $<75 \mathrm{U} / \mathrm{kg} / 2 \mathrm{wk}$ & 0.31 & 0.24 & 0.40 & \\
\hline 29 to $<48 \mathrm{U} / \mathrm{kg} / 2 \mathrm{wk}$ & 0.49 & 0.45 & 0.53 & $<0.01$ \\
\hline 5 to $<29 \mathrm{U} / \mathrm{kg} / 2 \mathrm{wk}$ & 0.61 & 0.56 & 0.67 & \\
\hline $\mathrm{T}_{50}$ & Months & & & \\
\hline 48 to $<75 \mathrm{U} / \mathrm{kg} / 2 \mathrm{wk}$ & 90.35 & 50.82 & 160.64 & \\
\hline 29 to $<48 \mathrm{U} / \mathrm{kg} / 2 \mathrm{wk}$ & 36.86 & 23.88 & 56.91 & $<0.01$ \\
\hline 5 to $<29 \mathrm{U} / \mathrm{kg} / 2 \mathrm{wk}$ & 23.55 & 13.57 & 40.86 & \\
\hline
\end{tabular}

p-value indicates statistical significance among dosing groups.

Fig. 4. Hepatic volume dose responses to enzyme therapy. A, Nonlinear mixed model showing the dose-response relationships of matched patients for hepatic volume. The $E_{\max }$ values were $0.61,0.49$, and 0.31 from baseline for the Group A ( 5 to $<29$ U/kg/2 weeks), Group B ( 29 to $<48$ U/kg/2 weeks), and Group C (48 to $<75$ U/kg/2 weeks) dosing groups, respectively, corresponding to reductions of $39 \%, 51 \%$, and $69 \%$ in hepatic volumes. In each dosing group, the numbers of data points after matching were 527 for Group A (red), 472 for Group B (black), and 340 for Group C (blue). $B$, Table of calculated values from (A) for maximal effect from baseline $\left(E_{\max }\right)$ and time to $50 \%$ of maximal effect $\left(T_{50}\right)$ responses to hepatic volume. The $P$ values and $95 \%$ confidence intervals are as in Figure 1, B.

imiglucerase. ${ }^{11-15,25,26}$ These previous studies were limited by small sample sizes, short periods of follow-up, and substantial heterogeneity within and among treatment groups; all of which may have limited the statistical power to identify dose-response relationships. The importance of long-term follow-up is highlighted from the results of this present study. In the first 6-12 months of follow-up, little distinction between treatment responses for the various dosing groups was seen except for platelets (Figs. 1-4). However, beyond 12-24 months, the dose-response relationships became more apparent.

The response parameters included in this analysis were those most commonly assessed in previous studies (hemoglobin concentration, platelet count, hepatic and splenic volume) and those that had the most longitudinal data available in the ICGG Gaucher Registry. However, skeletal disease is often the source of significant long-term morbidity. To achieve matched groups 
of adequate size, skeletal parameters were not included in this analysis. However, dose-dependent bone outcomes have been previously reported ${ }^{27,28}$ using alternative methods of analysis, with results consistent with the present study. In a retrospective analysis, ${ }^{29}$ a cohort of GD1 patients from Germany (where higher doses of enzyme therapy are typically used) was compared with a cohort from the Netherlands (where lower doses of enzyme therapy are typically used). The two groups were matched for baseline disease severity, and treatment response was compared across several parameters. The group receiving a higher dose of enzyme therapy had a more robust clearance of bone marrow infiltration of Gaucher cells and reductions in the biomarker chitotriosidase, but no dose-dependent differences were detected in effect on liver or spleen enlargement, anemia, or thrombocytopenia. ${ }^{29}$ These results were most likely due to the small numbers of matched pairs between the two cohorts for each parameter and the resulting limited statistical power. In another recent analysis of data from the ICGG Gaucher Registry, the effect of imiglucerase on bone mineral density in adults with GD1 was assessed, and statistically significant long-term dose-dependent effects on improvements in bone mineral density were found. ${ }^{30}$ On average, the patients who received imiglucerase at $60 \mathrm{U} / \mathrm{kg} / 2$ weeks achieved a normal bone mineral density after about 8 years of treatment. ${ }^{30}$

Importantly, significant parameter responses for $E_{\max }$ or $T_{50}$ were obtained for patients in all three dosing groups. In general, dose response was not expected to be reflected in the $T_{50}$ values because this is a response parameter for achievement of $50 \%$ of $E_{\text {max }}$, rather than the time to a $50 \%$ change from the baseline. Although not formally evaluated the $50 \%$ change from baseline values are evident from Figures 1-4. For platelet counts, comparative respective values in Groups $\mathrm{A}, \mathrm{B}$, and $\mathrm{C}$ are $T_{50} \sim 18$, 11 , and 5 months, and for a $50 \%$ increase $\sim 50,28$, and 19 months. For splenic volumes, the comparative respective values for Groups A, B, and C are: $T_{50} \sim 27,24$, and 54 months and for a $50 \%$ decrease $\sim 40,30$, and 22 months. Such comparative values cannot be obtained for liver volume because a $50 \%$ reduction was not, or barely, achieved in the time frame of the study for the Groups A and B. This cannot be explained by differences in liver volume at baseline, i.e., near normal values before enzyme therapy in one group compared with another, because the propensity score matching directly addressed this confounder. What then might explain the variations in responses at different doses and different times? Although there are no solid explanations, a reasonable assumption would be cognizant that the liver uptake of imiglucerase and alglucerase represents about $75-85 \%$ of the dose. 31,32 Thus, at lower doses, proportionately smaller amounts of administered enzyme would escape this trap, whereas at higher doses more enzyme could circulate to other organs. Greater effects might be anticipated on splenic volume reduction and the derivative effects on platelet counts with higher doses.

For a rare, chronic, heterogeneous disorder such as GD, a large multiarm randomized clinical trial of appropriate size and duration to investigate dose-response relationships may not be possible. However, observational data from an international rare disease registry make such analyses feasible within limits of voluntary observational databases. Application of propensity score matching created conditions similar to a randomized trial and minimized confounding because of differences in baseline severity between groups. Although originally designed for comparison of two groups, propensity scoring has been applied successfully to several defined groups. ${ }^{33,34}$ Nonlinear mixed effects modeling techniques were used to assess treatment responses over a long period of follow-up. ${ }^{19-22}$ However, smaller numbers of patients had assessments reported at the longer term time points, thereby potentially limiting the analyses. In addition, the parameter responses seem to converge, albeit slowly, during later years of follow-up. This methodology enabled analyses of larger, more homogeneous groups of patients with longer follow-up periods than previous studies and may overcome some of the challenges of small sample size, high degree of heterogeneity, and short periods of follow-up found in previous studies. ${ }^{11-15,25,26,29}$ The use of such epidemiologic matching and modeling methods to analyze observational data should have applicability to other rare disease registries.

This study has several potential sources of bias or confounding as with any study using observational data. Patients followed in the ICGG Gaucher Registry are not randomized to drug dose or protocol driven standard dosing, and treated patients are known to have more severe disease than untreated patients. However, the propensity score matching technique was used to minimize such bias in the treatment groups as shown in Table 1 between pre- and postmatching. Additionally, a potential limitation could be introduced by inclusion of less severely involved patients overall, because patients who received lower doses generally had less severe disease. As such, similarly less severe patients who received higher doses might have greater/ more robust responses than those similarly affected patients on lower doses. Although there is no direct way to address this issue in this study, the patients in the final matched groups were representative of the entire patient database of nonsplenectomized GD1 patients (Supplemental Digital Content 1, http://links.lww.com/A694). A more complete answer to this issue will require the use of validated severity indices that show sensitivity/responsiveness to therapy. A potential confounder includes the frequency of administration, which was not examined in this study, although most patients receive infusions every 2 weeks (ICGG Gaucher Registry, data on file).

This study provides strong evidence of incremental doseresponse relationships for enzyme therapy with alglucerase/ imiglucerase within the ranges of doses typically used across several of the main clinical parameters of GD1. This study was designed and executed to determine whether a dose-response exists for selected, clinically relevant disease parameters. The analyses were not specifically directed to address the clinical import of the resultant incremental dose responses. However, the data clearly show significant responses of each parameter within each of the dosing ranges. In addition, the apparent convergence of the response curves for each parameter to a plateau at years 5-8 indicates a potential maximal correction of the initial abnormalties by this time-which might be expected as each parameter normalizes. From such data, one cannot directly conclude that "general maintenance doses" are applicable in the later years of follow-up. There are individual patients in the authors' experiences who require long-term treatment at specific doses to "maintain" improvements in the present disease parameters and in health. Decreasing doses once maximal effects have been achieved should be assessed in the context of the overall health of the individual patient, e.g., there are patients in whom the four parameters assessed here do not seem to correlate with their overall health and quality of life. The development of a "severity index" that includes additional validated assessments of health and well being, including the important biomarkers of disease severity assessed here, may provide a clinical tool to make the responses to such dosage adjustments more objective. Similarly, the judgments of the clinical implications of the incremental dose responses determined here also requires such a standardized consensus agree- 
ment about the relationship of the present parametric changes and overall disease improvement.

For clinicians managing patients with GD1, these results may provide a basis for dosage selection and adjustment in specific clinical contexts. For example, the more rapid and greater responses in splenic volume decreases and platelet count increases within Group C, provide data to support use of such doses in patients with severe thrombocytopenia, massive splenomegaly, and bleeding. Also, the response characteristics within each dosing group provide benchmarks for treatment of patients who are not responding well to a chosen dose or who are not meeting expected therapeutic goals on a selected dose, ${ }^{18}$ because the present results provide overall expectations of responses and the time to achievement of specific improvements in these disease parameters.

Data from the ICGG Gaucher Registry provide evidence of dose-response relationships for enzyme therapy with imiglucerase/alglucerase within the range of doses (about 15-60 $\mathrm{U} / \mathrm{kg} / 2$ weeks) routinely used in clinical practice across several clinical parameters of GD1. The dose of enzyme therapy seems to affect not only the rate of the treatment effect but also the level of the $E_{\max }$ across these parameters. This study also demonstrates that observational data from an international rare disease registry can be analyzed using propensity scoring methods to match groups and nonlinear mixed effects models to assess dose-response relationships.

\section{ACKNOWLEDGMENTS}

We express our deep gratitude to many patients with Gaucher disease and their physicians and other health care providers around the world who submit data to the ICGG Gaucher Registry, the International Collaborative Gaucher Group (ICGG) for their review of the manuscript, the Gaucher Registry support team, Robert Brown for graphic design of the figures, and Peter L. Bonate, $\mathrm{PhD}, \mathrm{FCP}$ for his advice with nonlinear mixed effects modeling, and to Andrea Gwosdow for expert assistance in preparing the manuscript.

\section{REFERENCES}

1. Beutler E, Grabowski GA. Gaucher disease. In: Scriver CR, Beaudet AL, Sly WS, Valle D, Childs B, Kinzler KW, Vogelstein B, editors. The metabolic and molecular bases of inherited disease. New York: McGraw-Hill, 2001:3635-3668.

2. Brady RO, Kanfer J, Shapiro D. The metabolism of glucocerebrosides. I. Purification and properties of a glucocerebroside-cleaving enzyme from spleen tissue. J Biol Chem 1965;240:39-43.

3. Grabowski GA. Current issues in enzyme therapy for Gaucher disease. Drugs 1996;52:159-167.

4. Grabowski GA, Kolodny E, Weinreb NJ, et al. Gaucher disease: phenotypic and genetic variation, Chapter 146.1. In: Scriver CR, Beaudet AL, Sly WS, Valle D, editors. The online metabolic and molecular basis of inherited metabolic disease. New York: McGraw-Hill, 2006.

5. Zevin S, Abrahamov A, Hadas-Halpern I, et al. Adult-type Gaucher disease in children: genetics, clinical features and enzyme replacement therapy. $Q \mathrm{~J} \mathrm{Med}$ $1993 ; 86: 565-573$

6. Charrow J, Andersson HC, Kaplan P, et al. The Gaucher Registry: demographics and disease characteristics of 1698 patients with Gaucher disease. Arch Intern Med 2000;160:2835-2843.

7. Meikle PJ, Hopwood JJ, Clague AE, Carey WF. Prevalence of lysosomal storage disorders. JAMA 1999;281:249-254.

8. Grabowski GA, Barton NW, Pastores G, et al. Enzyme therapy in type 1 Gaucher disease: comparative efficacy of mannose-terminated glucocerebrosidase from natural and recombinant sources. Ann Intern Med 1995;122:33-39.
9. Barton NW, Brady RO, Dambrosia JM, et al. Replacement therapy for inherited enzyme deficiency - macrophage-targeted glucocerebrosidase for Gaucher's disease. $N$ Engl J Med 1991;324:1464-1470.

10. Gaucher disease. Current issues in diagnosis and treatment. NIH technology assessment panel on Gaucher disease. JAMA 1996;275:548-553.

11. Altarescu G, Schiffmann R, Parker CC, et al. Comparative efficacy of dose regimens in enzyme replacement therapy of type I Gaucher disease. Blood Cells Mol Dis 2000;26:285-290.

12. Figueroa ML, Rosenbloom BE, Kay AC, et al. A less costly regimen of alglucerase to treat Gaucher's disease. N Engl J Med 1992;327:1632-1636.

13. Hollak CE, Aerts JM, Goudsmit R, et al. Individualised low-dose alglucerase therapy for type 1 Gaucher's disease. Lancet 1995;345:1474-1478.

14. Pastores GM, Sibille AR, Grabowski GA. Enzyme therapy in Gaucher disease type 1: dosage efficacy and adverse effects in 33 patients treated for 6 to 24 months. Blood 1993;82:408-416.

15. Zimran A, Elstein D, Levy-Lahad E, et al. Replacement therapy with imiglucerase for type 1 Gaucher's disease. Lancet 1995;345:1479-1480.

16. Andersson $\mathrm{HC}$, Charrow J, Kaplan $\mathrm{P}$, et al. Individualization of long-term enzyme replacement therapy for Gaucher disease. Genet Med 2005;7:105-110.

17. Charrow J, Andersson HC, Kaplan P, et al. Enzyme replacement therapy and monitoring for children with type 1 Gaucher disease: consensus recommendations. J Pediatr 2004;144:112-120.

18. Weinreb NJ, Aggio MC, Andersson HC, et al. Gaucher disease type 1: revised recommendations on evaluations and monitoring for adult patients. Semin Hematol 2004;41:15-22.

19. Frangakis CE, Rubin DB. Principal stratification in causal inference. Biometrics 2002;58:21-29.

20. Rosenbaum P, Rubin D. The central role of the propensity score in observational studies for causal effects. Biometrika 1983;70:41-55.

21. Rubin DB. Bayesian inference for causal effects: the role of randomization. Ann Statist 1978;6:34-58.

22. Rubin DB, Neal T. Combining propensity scores matching with additional adjustments for prognostic covariates. J Am Stat Assoc 2000;95:573-585.

23. Elstein D, Hadas-Halpern I, Azuri Y, Abrahamov A, Bar-Ziv Y, Zimran A. Accuracy of ultrasonography in assessing spleen and liver size in patients with Gaucher disease: comparison to computed tomographic measurements. $J$ Ultrasound Med 1997;16:209-211.

24. Holford NH, Sheiner LB. Understanding the dose-effect relationship: clinical application of pharmacokinetic-pharmacodynamic models. Clin Pharmacokinet 1981;6:429-453.

25. Barton NW, Furbish FS, Murray GJ, Garfield M, Brady RO. Therapeutic response to intravenous infusions of glucocerebrosidase in a patient with Gaucher disease. Proc Natl Acad Sci USA 1990;87:1913-1916.

26. Beutler E. Dosage-response in the treatment of Gaucher disease by enzyme replacement therapy. Blood Cells Mol Dis 2000;26:303-306.

27. Ciana G, Addobbati R, Tamaro G, et al. Gaucher disease and bone: laboratory and skeletal mineral density variations during a long period of enzyme replacement therapy. J Inherit Metab Dis 2005;28:723-732.

28. Wenstrup RJ, Bailey L, Grabowski GA, et al. Gaucher disease: alendronate disodium improves bone mineral density in adults receiving enzyme therapy. Blood 2004;104:1253-1257.

29. de Fost M, Hollak CE, Groener JE, et al. Superior effects of high-dose enzyme replacement therapy in type 1 Gaucher disease on bone marrow involvement and chitotriosidase levels: a 2-center retrospective analysis. Blood 2006;108:830-835

30. Wenstrup RJ, Kacena KA, Kaplan P, et al. Effect of enzyme replacement therapy with imiglucerase on BMD in type 1 Gaucher disease. J Bone Miner Res 2007;22:119-126.

31. Bijsterbosch MK, Donker W, van de Bilt H, van Weely S, van Berkel TJ, Aerts JM. Quantitative analysis of the targeting of mannose-terminal glucocerebrosidase. Predominant uptake by liver endothelial cells. Eur J Biochem 1996;237:344-349.

32. $\mathrm{Xu} \mathrm{YH,} \mathrm{Ponce} \mathrm{E,} \mathrm{Sun} \mathrm{Y,} \mathrm{et} \mathrm{al.} \mathrm{Turnover} \mathrm{and} \mathrm{distribution} \mathrm{of} \mathrm{intravenously}$ administered mannose-terminated human acid beta-glucosidase in murine and human tissues. Pediatr Res 1996;39:313-322.

33. McAfee AT, Koro C, Landon J, Ziyadeh N, Walker AM. Coronary heart disease outcomes in patients receiving antidiabetic agents. Pharmacoepidemiol Drug Saf 2007;16:711-725.

34. Wang J, Donnan PT, Steinke D, MacDonald TM. The multiple propensity score for analysis of dose-response relationships in drug safety studies. Pharmacoepidemiol Drug Saf 2001;10:105-111. 